\title{
Status Epilepticus and Beyond: A Clinical Review of Status Epilepticus and an Update on Current Management Strategies in Super-refractory Status Epilepticus
}

\author{
Roy Poblete and Gene Sung \\ Department of Neurology, Keck School of Medicine of the University of Southern California, Los Angeles, CA, USA
}

Status epilepticus and refractory status epilepticus represent some of the most complex conditions encountered in the neurological intensive care unit. Challenges in management are common as treatment options become limited and prolonged hospital courses are accompanied by complications and worsening patient outcomes. Antiepileptic drug treatments have become increasingly complex. Rational polytherapy should consider the pharmacodynamics and kinetics of medications. When seizures cannot be controlled with medical therapy, alternative treatments, including early surgical evaluation can be considered; however, evidence is limited. This review provides a brief overview of status epilepticus, and a recent update on the management of refractory status epilepticus based on evidence from the literature, evidence-based guidelines, and experiences at our institution.

Key Words: anticonvulsants; intensive care; pharmacokinetics; seizures; status epilepticus.

\section{Background}

\section{1) Introduction}

Status epilepticus (SE) and refractory SE (RSE) are some of the most complex and expensive conditions encountered in the neurological intensive care unit (ICU). For example, in the United States, SE represents $0.07 \%$ of hospital admissions [1], but accounts for a larger proportion of hospital costs, including \$4 billion in direct inpatient costs annually [2] with a mean length of stay of 14 days [2,3]. In those who fail to respond to conventional treatments, costs increase exponentially in proportion to treatment intensity. RSE provides diagnostic, management, and ethical challenges as treatment options become limited and prolonged hospital stays are accompanied by several potential complications and worse patient outcomes. This review provides a brief overview of SE, and a recent update on the management of RSE and super-RSE (SRSE) based on evidence from the literature, practice-based guidelines, and experiences at Keck Medical Center of the University of Southern California, an academic tertiary care center.

Received on February 7, 2017 Accepted on May 5, 2017

Correspondence to: Gene Sung, Department of Neurology, Keck School of Medicine of the University of Southern California, 1100 North State Street, Los Angeles, CA 90033, USA

Tel: +1-323-409-8552, Fax: +1-323-441-8063, E-mail: gsung@usc.edu

*No potential conflict of interest relevant to this article was reported.

cc This is an Open Access article distributed under the terms of the Creative Commons Attribution Non-Commercial License (http://creativecommons.org/ licenses/by-nc/4.0/) which permits unrestricted non-commercial use, distribution, and reproduction in any medium, provided the original work is properly cited. Copyright (c) 2017 The Korean Society of Critical Care Medicine 


\section{2) Definitions}

Early definitions of SE described seizures persisting "for a sufficient length of time or is repeated frequently enough to produce a fixed or enduring epileptic condition [4]." A more practical definition was introduced in 1993 as a "seizure lasting more than 30 minutes or occurrence of two or more seizures without recovery of consciousness in between [5]." This somewhat arbitrary timeframe was based on animal models suggesting irreversible neuronal injury with prolonged seizure [6]. Conceptually, SE describes "a condition resulting either from the failure of the mechanisms responsible for seizure termination or from the initiation of mechanisms which lead to abnormally prolonged seizures," as proposed by the International League Against Epilepsy Task Force on Classification of Status Epilepticus [7]. A pragmatic definition of $\mathrm{SE}$ as a seizure " $\geq 5$ minutes or two or more discreet seizures between which there is incomplete recovery of consciousness" was proposed by Lowenstein and Alldredge [8], and has largely been adopted by clinicians and clinical researchers. Based on the pathophysiology of SE described later, this definition is most useful and is endorsed by the Neurocritical Care Society (NCCS) Status Epilepticus Guideline Writing Committee [9].

SE fails to respond to standard medications in $31 \%$ to $43 \%$ of cases $[10,11]$. Although there is no consensus definition of RSE, it typically describes SE refractory to early benzodiazepines and one additional first-line antiseizure medication. If seizures cannot be terminated with the use of an intravenous (IV) anesthetic in addition to benzodiazepines and standard anticonvulsants, the condition is termed SRSE. Relatively uncommon, up to $15 \%$ of SE cases become super-refractory [12], accounting for $4 \%$ of seizure-related hospital discharges [13]. As RSE and SRSE are commonly treated with therapeutic coma, signs of seizure become clinically absent. When electrographic seizures are not accompanied by corresponding motor movements, or by subtle motor signs, the term nonconvulsive SE (NCSE) is used. New-onset RSE (NORSE) describes RSE in previously healthy individuals where no cause of SE is immediately apparent [14].

\section{Causes and Pathophysiology}

\section{1) Causes}

SE and RSE most often occur in patients with known epilepsy. Up to $34 \%$ of SE cases are attributed to low anticonvulsant drug levels $[10,15]$, due to suboptimal dosing, medication non-compliance, or recent medication change. In those without epilepsy, etiology varies significantly by age. In adults, other leading causes of SE include stroke, toxic-metabolic encephalopathy, and hypoxic-ischemic injury, while tumor and meningoencephalitis account for only $4 \%$ to $5 \%$ of RSE cases [10]. In comparison, central nervous system (CNS) infection is the leading cause of SE in children, with trauma and anoxic injury as other major etiologies $[16,17]$.

Regardless of age, seizure etiology is not found in a large portion of patients. An analysis of 130 cases of NORSE by Gaspard et al. [14] determined that despite exhaustive search, $52 \%$ remained cryptogenic. In such cases, patients are commonly treated for presumed infectious, autoimmune or paraneoplastic encephalitis; however, an infectious agent is rarely found [18]. Similarly, neuropathologic study with biopsy or autopsy is often inconclusive [19-22].

\section{2) Pathophysiology}

\section{(1) Biochemical phases of SE}

Seizures result from disruptions in the normal balance of excitatory and inhibitory processes. Hypersynchronous neuronal firing, the physiologic hallmark of seizure, is mediated predominantly by glutamate excitation and voltage-gated sodium and calcium channels. Seizure termination is largely dependent on the inhibitory effects of gamma-aminobutyric acid (GABA)-receptor activation and voltage-gated potassium channels [23]. After initiation, failure of intrinsic mechanisms or disruption of inhibition from extrinsic factors will lead to prolonged seizure activity. The maintenance phase of SE is characterized by synaptic internalization of GABA receptors and expression of excitatory N-methyl-D-aspartate (NMDA) and 
alpha-amino-3-hydroxy-5-methyl-4-isoxazolepropionic acid receptors, resulting in self-sustaining seizures refractory to conventional antiepileptic drugs (AEDs) [24]. In animal models, the potency of benzodiazepines decrease 20-fold within 30 minutes of SE, while phenytoin loses effectiveness to a lesser degree [25]. Observations in humans suggest that a refractory state is reached much faster. In a video electroencephalogram (EEG) study of 120 generalized convulsive seizures, the mean seizure duration was 62 seconds with no events lasting $>2$ minutes [26]. In clinical practice, seizures are less likely to terminate spontaneously after this period, leading to Lowenstein and Alldredge [8] proposing SE be defined as continuous seizure for $\geq 5$ minutes. In the minutes-to-hours that follow, SE is maintained by increased expression of proconvulsive neuropeptides and decrease in inhibitory ones [27-30].

Less is known about the biochemical changes associated with RSE and SRSE. In the range of hours-to-weeks, long-term changes in gene expression may occur secondary to recurrent seizure activity and neuronal injury, resulting in neural reorganization [24].

\section{(2) Neuronal injury and death}

Neuronal loss in SE was described in early foundational work in primate models by Meldrum and Horton [6] and Meldrum et al. [31]. Cell death occurs even in the absence of hypoxia, acidosis, hypoglycemia and other confounding factors [32-34], and may be mediated by 'programmed necrosis' and apoptosis $[35,36]$. In humans, serum neuron-specific enolase, a biomarker for neural injury, has been shown to be elevated in SE [37,38], while autopsy studies demonstrate decreased hippocampal neuron density postmortem [39].

To what extent similar pathologic changes occur in NCSE as compared to convulsive SE (CSE) is unclear. Early observational studies by Engel et al. [40] suggested long-standing neurocognitive changes following NCSE. Serum neuron-specific enolase has also been shown to be elevated [37,41,42]; however, it is difficult to determine whether NCSE directly causes neuronal injury, or if sei- zures reflect brain damage from other causes. NCSE also represents a heterogenous syndrome, with potential for neuronal injury dependent on the seizure type and etiology. Absence SE and NCSE in patients with underlying chronic epilepsy may be less prone to injury $[43,44]$, while complex partial SE is most associated with pathologic changes [40-42].

\section{(3) Physiologic phases of SE}

Patients with CSE progress through physiologic stages [45]. In the early compensated phase, convulsions are accompanied by significant sympathetic activation. During this stage, hypertension, increased cardiac output, and increased cerebral blood flow is seen, and serum markers of hypermetabolism such as lactic acid and glucose will be elevated [46]. After prolonged seizure activity $(>30$ minutes), pathophysiologic decompensation occurs. This is characterized by cerebral dysautoregulation, cardiovascular dysfunction, and signs of systemic metabolic crisis: hypoxia, hypoglycemia, and acidosis. Failure to prevent profound physiologic disturbances may exacerbate secondary brain injury associated with RSE.

\section{Diagnosis}

\section{1) Clinical findings}

Differentiating seizure from mimics by clinical exam alone can be difficult. In hospitalized patients with encephalopathy out of proportion to known laboratory and imaging findings, non-convulsive seizures can be detected by continuous EEG (cEEG) in up to $18 \%$ [47]. Nonspecific motor movements, including posturing, rigidity, shivering, tremor, myoclonus, and spontaneous gaze deviation, can be misinterpreted as seizure. Facial twitching is associated with a higher incidence of electrographic seizures compared to other subtle signs [48].

\section{2) The use of EEG}

Because of the limitations of clinical exam in diagnosing seizures, EEG confirmation is necessary in many 
cases. Suspicion for SE should be higher in the critically ill, where seizure complicates the ICU stay of $8 \%$ to $10 \%$ of patients $[49,50]$. In the neuro-ICU, the incidence of seizure can exceed $30 \%$, with NCSE occurring in up to $13 \%$ [51,52]. Eight percent of those with coma without obvious seizure activity have NCSE on cEEG [53].

In response, the use of cEEG has expanded. Indications for extended monitoring and the optimal study duration is unknown; however, early EEG findings can predict final diagnosis. The majority of seizures occur within the first 30 minutes of recording [54]. In this timeframe, generalized slowing is poorly predictive of seizure while lateralized periodic discharges has the strongest association [55]. In the absence of epileptiform discharges within the first 4 hours of EEG, seizures are unlikely to be found [56].

\section{Conventional Management of RSE}

Effective management of SE and RSE occurs in three phases: seizure termination, prevention of SE recurrence, and minimization of complications. This is a dynamic process, where complications occur during all clinical stages and treatment plans should be adapted for seizure recurrence and new diagnostic findings. An initial treatment strategy simultaneously addresses airway, breathing and circulation while intervening quickly to abort seizure activity within 5 minutes of onset [9].

\section{1) Seizure termination in SE}

\section{(1) Stage I treatment: benzodiazepine trial}

As described above, seizures are associated with profound pathophysiologic changes, that if left untreated, can lead to severe clinical consequences. When convulsive seizures occur, attention should be given to both basic life support measures while considering first line AED therapy. Evidence-based guidelines from both the NCCS and the American Epilepsy Society (AES) recommend benzodiazepines as initial therapy of choice $[9,57]$. Lorazepam is widely available, fast to administer, and terminates overt SE in $65 \%$ of cases [58]. Compared to diazepam, IV lorazepam is pharmacologically preferred because it is less lipid soluble and undergoes slower peripheral distribution [59]. Intramuscular midazolam is effective when IV access has not been established.

Recurrent convulsive seizures in RSE and SRSE are treated similarly. In intubated patients, full-dose lorazepam $(0.1 \mathrm{mg} / \mathrm{kg})$ or equivalent benzodiazepine can be given, with smaller doses considered when attempting to avoid intubation or when significant hypotension is present.

\section{(2) Stage II treatment: first-line conventional AEDs}

Benzodiazepines lose effectiveness in established SE and are suboptimal for long-term anti-seizure management; therefore, next-line AEDs should be ordered and administered early, within 10 minutes of seizure onset [9]. First-line conventional AEDs are selected for their broad spectrum of activity and their ability to be given safely as an IV loading dose in attempts to abort SE and reach therapeutic levels rapidly (Table 1 ).

Historically, phenytoin has been the initial stage II AED given after benzodiazepines, terminating overt seizure in $44 \%$ in the Veterans Affairs Cooperative Study [58]. Many clinical concerns may limit its use. Phenytoin is not considered sedating; however, hypotension and cardiac arrhythmia can occur with bolus doses [60]. Other acute complications include 'purple glove syndrome' and metabolic acidosis, while long-term side effects including teratogenicity and coarsening of facial features make it nonideal for chronic therapy. Phenytoin is also limited by its narrow therapeutic range. Additionally, bioavailability is influenced by factors common to ICU patients: drug-drug interactions, renal insufficiency, and hypoalbuminemia.

For many neurointensivists, levetiracetam has been explored as a stage I and II AED in SE. Preferred pharmacologic properties include its high bioavailability and few drug-drug interactions owing to low plasma protein binding and minimal hepatic metabolism [61]. Unfortunately, data for levetiracetam as an emergent treatment is limited. In a pilot study involving traditional AEDs, 
Table 1. Non-benzodiazepine first-line and second-line antiepileptic medications

\begin{tabular}{|c|c|c|c|}
\hline Drug & Initial dose & Initial maintenance dose & Clinical consideration \\
\hline \multicolumn{4}{|c|}{ First-line scheduled antiepileptic drug } \\
\hline Phenytoin/fosphenytoin & 15-20 mg/kg IV & $100 \mathrm{mg}$ every $8 \mathrm{~h}$ & $\begin{array}{l}\text { Narrow therapeutic range; calculated levels should be cor- } \\
\text { rected for reduced GFR and hypoalbuminemia. }\end{array}$ \\
\hline Levetiracetam & $30 \mathrm{mg} / \mathrm{kg}$ IV & 500-1,000 mg every $12 \mathrm{~h}$ & $\begin{array}{l}\text { Few drug interactions; may cause agitation; unclear how rapid } \\
\text { CNS penetration is }\end{array}$ \\
\hline Valproic acid & 20-30 mg/kg IV & 500 mg every 12 h & $\begin{array}{l}\text { May increase bleeding risk due to thrombocytopenia, reduced } \\
\text { fibrinogen; high teratogenicity }\end{array}$ \\
\hline Phenobarbital & 10-20 mg/kg IV bolus & $1 \mathrm{mg} / \mathrm{kg}$ every $12 \mathrm{~h}$ & $\begin{array}{l}\text { High dose phenobarbital can aid in weaning off anesthetic } \\
\text { agents. Patients can develop drug tolerance while maintain- } \\
\text { ing therapeutic levels. }\end{array}$ \\
\hline \multicolumn{4}{|c|}{ Second-line scheduled antiepileptic drug } \\
\hline Lacosamide & 200-400 mg IV & 200 mg every $12 \mathrm{~h}$ & $\begin{array}{l}\text { Associated with PR-prolongation on electrocardiogram; few } \\
\text { drug interactions }\end{array}$ \\
\hline Topiramate & $200-400$ mg P0 & $300 \mathrm{mg}$ every $6 \mathrm{~h}$ & May be sedating; cannot be rapidly titrated \\
\hline Gabapentin & 300-900 mg P0 & 300-900 mg every $8 \mathrm{~h}$ & Few drug interactions; useful in patients with neuropathic pain \\
\hline
\end{tabular}

First-line agents are commonly chosen for their ability to be given safely as an IV loading dose. Third line antiepileptic drugs include carbamazepine, oxcarbamazepine, zonisamide, vigabatrin, rufinamide, ezogabine, and perampanel.

IV: intravenous; GFR: glomerular filtration rate; CNS: central nervous system; PO: per oral

Table 2. Anesthetic infusions used for definite treatment of refractory status epilepticus

\begin{tabular}{lccc}
\hline Drug & Loading dose $(\mathrm{mg} / \mathrm{kg})$ & Maintenance dose $(\mathrm{mg} / \mathrm{kg} / \mathrm{h})$ & \multicolumn{1}{c}{ Clinical consideration } \\
\hline $\begin{array}{l}\text { Propofol } \\
\text { Midazolam }\end{array}$ & $0.2-2.0$ & $\begin{array}{c}\text { Rapid onset and offset facilitates neurologic examination; monitoring for } \\
\text { propofol infusion syndrome with extended use }\end{array}$ \\
$\begin{array}{l}\text { Ketamine } \\
\text { Pentobarbital }\end{array}$ & $-1-0.3$ & $\begin{array}{c}\text { Alternate to propofol that may cause less cardiovascular depression; as- } \\
\text { sociated with tachyphylaxis and drug accumulation }\end{array}$ \\
\hline
\end{tabular}

On initiation, anesthetic agents should be given as a bolus dose to reach therapeutic drug concentrations early.

levetiracetam demonstrated equal efficacy in aborting overt seizure compared to lorazepam [62], and in a recent meta-analysis, showed similar activity in benzodiazepineresistant SE (68.5\% relative effectiveness) compared to phenytoin $(50.2 \%)$, phenobarbital (73.6\%), and valproic acid (75.7\%) [63]. The drug is well tolerated, ideal in critically ill patients on multiple medications, and for longterm therapy in those who remain at risk for seizures after hospital discharge.

\section{(3) Stage III treatment: termination of RSE seizures}

Optimal therapy after failure of benzodiazepines and first stage II AED is unknown. Although a second con- ventional AED is typically added in this setting, the likelihood of success is marginal and may delay seizure termination. Development of RSE should prompt planning for ICU admission, intubation, and initiation of a general anesthetic agent. Seizure activity is definitively aborted with use of a single anesthetic agent, or with combination of agents in SRSE, with no method or agent proven superior to another $[12,64]$. Anesthetic drugs used are outlined in Table 2.

Whether propofol or midazolam are used first largely depends on provider preference. Propofol, a GABA agonist and NMDA-receptor antagonist, is often preferred because its highly lipophilic properties with large volume 
of distribution allow for rapid offset to facilitate neurologic examination. In patients with hypotension with or without propofol, midazolam is an alternate; however, it itself is associated with hypotension in $40 \%$ of patients and may exhibit either tachyphylaxis or drug accumulation resulting in prolonged sedation $[65,66]$. Adequate EEG suppression may be difficult to achieve with a single anesthetic agent.

Because of its side effect profile, pentobarbital is typically reserved for cases of SRSE refractory to combined propofol and midazolam. Pentobarbital infusion can result in profound hypotension, cardiorespiratory depression, metabolic acidosis, and immunosuppression [67,68], which may outweigh any potential benefit of the drug. In a systematic review of outcomes in RSE and SRSE, barbiturate infusion achieved seizure control in 64\%, but was associated with prolonged mechanical ventilation and increased mortality [12]. Whether poorer outcomes are due to the therapy and its complications, or a result of SRSE being associated with more severe illness is unclear.

\section{2) Goals of EEG suppression}

Continuous EEG is fundamental to RSE management, and by AES guidelines, is recommended initially for all patients requiring anesthetics [57]. Because prolonged seizure is associated with electromechanical dissociation, where electrographic seizure no longer manifests overt clinical signs, successful termination is determined by EEG suppression. In SRSE, 'burst suppression' is typically maintained for an extended period; however, there is little evidence for efficacy of this practice, including the optimal level and duration of suppression. In a retrospective review by Krishnamurthy and Drislane [69] of 35 patients treated with pentobarbital infusion, "slow," "burstsuppression" and "flat" EEG patterns were not strongly associated with the rate of seizure relapse. Similarly, a retrospective study by Rossetti et al. [70] suggested that outcome after RSE was independent of the extent of EEG suppression achieved. Meta-analysis of 193 RSE patients support these conclusions: despite EEG background suppression being associated with fewer breakthrough seizures compared to seizure suppression alone (4\% and $53 \%$, respectively), the study found no difference in withdrawal seizures after AED weaning, or in mortality [64].

In the absence of high quality evidence, it is reasonable to titrate anesthetic agents to termination of ictal activity. If accomplished by reaching a diffusely slow EEG pattern, further suppression may not be needed. In the presence of persistent seizure or continuous epileptiform discharges, it is reasonable to consider suppression to one burst of EEG activity ( $<2$ seconds duration) every 10-20 seconds, and to continue that depth for 12-48 hours before initiating an anesthetic wean.

\section{An Update on Management Strategies for SRSE}

After seizure termination, general anesthetics do not ensure freedom from relapse. Up to $15 \%$ of SE cases become SRSE [12], typically diagnosed with recurrence of ictal activity when anesthetic drugs are titrated down. With little high-quality data to guide therapy, and high complication rates, the management of SRSE can be challenging. The remainder of this review will provide a recent update on practice recommendations, based on expert opinion, limited data, and experiences at our institution. With the lack of compelling evidence, the NCCS offers only weak recommendations for SRSE management, while it is the beyond the scope of most recent AES guidelines [9,57].

\section{1) Optimizing scheduled antiepileptic drugs}

Appropriate management of multiple AEDs requires basic knowledge of drug mechanisms and pharmacokinetics. Drug properties to consider when choosing an agent include its formulation, speed of CNS penetration, protein binding, volume of distribution, presence of autoinduction, drug-drug interactions, half-life, and elimination kinetics [71].

\section{(1) Adequate therapeutic dosing}

There are several reasons why AEDs fail to prevent sei- 
zure recurrence in SRSE. Although an epileptogenic focus may be refractory to certain medications, subtherapeutic drug levels commonly contribute to their ineffectiveness. AED levels should be checked serially throughout the early phase of SRSE, with titration of AEDs as appropriate.

Loading doses are given at drug initiation to reach therapeutic range early. AEDs with linear pharmacokinetics and low protein-binding can be loaded with greater predictability than those without such properties. Phenytoin, in contrast to levetiracetam, demonstrates non-linear kinetics and is highly protein-bound, making therapeutic ranges difficult to achieve and maintain. Patient weight influences volume of distribution; therefore, weight-based dosing should be given when established. Similarly, general anesthetics should be bolused on initiation. Propofol is given as a $2-5 \mathrm{mg} / \mathrm{kg}$ bolus, midazolam as a $0.2 \mathrm{mg} / \mathrm{kg}$ bolus, and pentobarbital with $5-10 \mathrm{mg} / \mathrm{kg}$.

Drug bioavailability should be considered when choosing IV versus oral (PO) routes of administration. Although bioavailability of many first-line AEDs such as phenytoin, valproate, and levetiracetam is high in healthy subjects [71,72], alterations in gastric motility, gut absorption and drug metabolism in the critically ill likely interfere [73]. In a study of IV versus PO phenytoin loading, IV doses resulted in faster times to therapeutic drug concentrations ( $0.21 \pm 0.28$ hours) compared to PO (5.63 \pm 0.28 hours) [74]. At our institution, IV formulations are typically continued until seizure termination and relapse has not occurred, and additionally during significant gastrointestinal illness.

Failure to account for the half-life of an AED can result in sub-therapeutic drug troughs. Clinically, this can be observed as EEG suppression after drug dosing, but recurrent seizure or increased frequency of epileptiform discharges prior to next administration. In highly-tolerated medications with shorter half-lives, such as levetiracetam and valproate, dosing every 8 hours instead of twice daily should be considered. In cases of polytherapy, AEDs can be scheduled in staggered fashion to prevent long spans between drug doses.

\section{(2) Drug polytherapy}

Patients failing benzodiazepines and first-line scheduled AEDs are unlikely to achieve seizure termination without anesthetics; however, in SRSE, polytherapy is necessary to prevent seizure recurrence. Managing multiple AEDS requires consideration of several factors: risks and benefits of treatment, dosing strategies, and drug-drug interactions that alter drug efficacy and metabolism, and potentiate side effects. Second and third-line agents are listed in Table 1.

In general, AEDs fall in to two broad categories: enzyme-inducers and enzyme-inhibitors. Table 3 categorizes commonly used AEDs. Concurrent use of an enzymeinducer and inhibitor can become problematic. This most commonly occurs when phenytoin, phenobarbital, or carbamazepine (inducers) are used in conjunction with valproic acid (an inhibitor), leading to supratherapeutic inducer levels and reductions in valproate concentrations by up to $50 \%-75 \%$ [75]. Free phenytoin, the active component of phenytoin, also increases with displacement from protein binding sites by valproate [76]. Increases in serum drug concentrations can result in toxicities at doses lower than expected. Carbamazepine, a second-line agent in SRSE, demonstrates auto-induction, where higher doses can result in increased drug metabolism [71].

\section{(3) AED mechanism of action}

In polytherapy, the most effective regiments consider the pharmacokinetic properties and mechanisms of drug actions (MOAs). There is no proven benefit of one AED

Table 3. Broad classification of antiepileptic drugs as significant enzyme inducers or inhibitors

\begin{tabular}{|c|c|}
\hline Enzyme inducer & Enzyme inhibitor \\
\hline Phenytoin & Valproic acid \\
\hline Primidone & Zonisamide ${ }^{a}$ \\
\hline \multicolumn{2}{|l|}{ Phenobarbital } \\
\hline \multicolumn{2}{|l|}{ Carbamazepine } \\
\hline $\begin{array}{l}\text { Many antiepileptic dr } \\
\text { or inhibit the activity c } \\
\text { aThe addition of zon } \\
\text { epoxide only. }\end{array}$ & $\begin{array}{l}\text { nt of status epilepticus induce } \\
\text { rease of the carbamazepine- } \\
\text {. }\end{array}$ \\
\hline
\end{tabular}


MOA compared to another in the treatment of SRSE. Similarly, no large study has investigated the efficacy of combining AEDs of different MOAs; however, this strategy is rationale, with early research suggesting polytherapy can be more effective and less toxic than monotherapy [77]. Use of consecutive AEDs with different MOAs is increasingly being employed in RSE protocols [78], and is common practice at our institution.

First-line scheduled AEDs are typically sodium channel blockers (phenytoin), or have a broad spectrum of action (valproic acid, levetiracetam) [79]. The established MOAs of AEDs is outlined in Table 4. Some medications listed, including perampanel and ezogabine, have not yet been established in the treatment of SE, but are occasionally used at our hospital for SRSE given their novel MOA and overall tolerability. Although SE is often refractory to benzodiazepines, addition of a scheduled GABAergic benzodiazepine can be useful, especially in patients demonstrating responsiveness to midazolam infusion.

\section{2) Developments in antiepileptic drug therapy for RSE}

The development new AEDs for the treatment of SE has focused on optimizing drug pharmacodynamics and kinetics. Innovations in finding new molecular targets and advances in drug delivery systems has been promising.

\section{(1) New and investigational antiepileptic drugs}

\section{Brivaracetam}

Brivaracetam has received 2016 approval in the United States and Europe for adjunctive therapy for partial seizures with potential application to the treatment of SE. It is a novel synaptic vesicle protein $2 \mathrm{~A}$ (SV2A) ligand that has 10 - to 20 -fold higher affinity for its target compared to levetiracetam [80], with faster CNS entry and onset of activity [81]. In experimental models, brivaracetam has shown potent anticonvulsant properties, acting synergistically with ketamine and benzodiazepines in SE [77,82]. Further clinical experience with this new AED are needed, including trials investigating its efficacy in SE and RSE.

Table 4. Mechanism of action of scheduled antiepileptic drugs used in refractory status epilepticus

\begin{tabular}{|c|c|c|c|c|c|c|}
\hline Drug & GABA-agonist & Glutamate antagonism & $\mathrm{Na}^{+}$channel & $\mathrm{Ca}^{+}$channel & CA-inhibition & Other \\
\hline Benzodiazepines & 0 & & & & & \\
\hline Phenytoin & & & 0 & 0 & & \\
\hline Levetiracetam & & & & $\bigcirc$ & & Presynaptic SV2A ligand \\
\hline Phenobarbital & 0 & 0 & & 0 & & \\
\hline Valproate & $\bigcirc$ & & $\bigcirc$ & $\bigcirc$ & & \\
\hline Lacosamide & & & 0 & & & Modulates CRMP2 protein \\
\hline Topiramate & $\bigcirc$ & $\bigcirc$ & $\bigcirc$ & $\bigcirc$ & $\bigcirc$ & \\
\hline Gabapentin & 0 & & & 0 & & \\
\hline Carbamazepine & 0 & $\bigcirc$ & O & & & \\
\hline Oxcarbamazepine & & 0 & $\bigcirc$ & 0 & & \\
\hline Zonisamide & & & $\bigcirc$ & 0 & 0 & \\
\hline Vigabatrin & 0 & & & & & \\
\hline Rufinamide & & & 0 & & & \\
\hline Ezogabine & $\bigcirc$ & & & & & $\begin{array}{l}\text { Modulates voltage-gated potassium } \\
\text { channels }\end{array}$ \\
\hline Perampanel & & & & & & $\begin{array}{l}\text { Postsynaptic AMPA-receptor an- } \\
\text { tagonism }\end{array}$ \\
\hline
\end{tabular}

Medications commonly have a predominant mechanism of action, but may show anti-seizure activity by other secondary mechanisms. GABA: gamma-aminobutyric acid; CA: carbonic anhydrase; SV2A: synaptic vesicle protein 2A; CRMP2: collapsing-response mediator protein 2; AMPA: alpha-amino3-hydroxy-5-methyl-4-isoxazoleproprionic acid. 


\section{Allopregnanolone}

Allopregnanolone is a neurosteroid that modulates GABA-A receptors at both synaptic and extrasynaptic sites, increasing tonic neuronal inhibition [83]. Its efficacy in treating SRSE has been demonstrated in human case studies, allowing for successful weaning off anesthetics in both adults and children [84,85]. Given these results and the limited available therapies in SRSE, allopregnanolone is currently being studied in an international randomized, placebo-controlled phase III trial [86].

\section{Other drugs under investigation}

Several other drugs have shown efficacy in animal models of SE, but are not yet widely available for human use. Valproic acid analogs, valnoctamide and sec-Butylpropylacetamide demonstrate broad spectrum anti-seizure activity and ability to terminate SE $[87,88]$. Carisbamate also shows broad spectrum of activity in seizure models by a yet undefined MOA that appears to be different than other established AEDs [89]. Preclinical data suggests carisbamate may protect against SE-induced neuronal damage [90].

\section{(2) New applications of established medications}

\section{Ketamine}

Ketamine is an IV anesthetic for definitive seizure termination in SRSE that modulates GABA-A receptors and acts as a NMDA-receptor antagonist. Although there are no randomized controlled trials to support its use, there have been two case series and a number of case reports suggesting an overall success rate of up to $56 \%$ in RSE $[59,91,92]$. In these studies, a median of five AEDs were used prior to ketamine infusion [59]. The absence of cardiovascular depression with ketamine is appealing in patients receiving polytherapy; however, it may be associated with hypertension in a majority of cases [93]. In our experience, the addition of ketamine can allow for reductions in other anesthetic agents and avoidance of serious hypotensive episodes.

\section{Inhaled anesthetics}

Isoflurane and desflurane are inhaled halogenated anesthetics with reported use in SE. Its ability to rapidly terminate seizure activity and achieve EEG suppression through uncomplicated drug titration is suggested from previous case series $[94,95]$; however, its widespread use has been limited. Side effects may be common and lifethreatening, including severe hypotension and paralytic ileus, and machinery needed to administer the drug was not practical in most ICUs. The increasing availability of small self-contained vaporizers may result in new interest in this treatment modality. A recent case report suggests the efficacy of isoflurane in combination with mild hypothermia for SRSE [96]; however, the safety of inhaled anesthetics requires further study in larger trials.

\section{3) Additional treatments for SRSE}

\section{(1) Non-surgical treatments}

\section{Immunotherapy}

Immunotherapy in SRSE, even in the absence of any identifiable immunologic disease, may be reasonable in select cases. Of continued research interest, cerebral inflammation is an important pathologic process in SE that exacerbates neuronal damage and contributes to epileptogenesis [97,98]. Despite many cases of NORSE and SRSE remaining cryptogenic in etiology $[14,18]$, immunotherapy can be empirically offered for treatment of occult autoimmune or paraneoplastic encephalitis, or other inflammatory disorder. Given the absence of high-quality evidence for this practice, the role of immunotherapy in SRSE is still unclear.

If provided, treatment typically begins with high-dose steroids ( $1 \mathrm{~g}$ IV methylprednisolone for 3 to 7 days). If there is no response to corticosteroids, plasma exchange or IV immunoglobulins over 3 to 5 sessions or doses may be employed. With partial response to immunotherapy and high suspicion for an underlying inflammatory disease, longstanding-immunotherapy can be continued with maintenance prednisone or other immunomodulators such as rituximab and cyclophosphamide [99]. Given the 
side effects associated with these medications, risks and benefits of therapy should be considered.

\section{Ketogenic diet}

A ketogenic diet (4:1 ratio of fat-to-carbohydrate and protein) has both anti-seizure and anti-inflammatory effects, making it an appealing adjunct to AEDs [99]. Although largely studied in the pediatric population, given promising results, it has been similarly applied to adults. In a series of 10 patients with SRSE treated with ketogenic diet, nine patients achieved ketosis and SE termination in a median of 3 days [100]. A recent meta-analysis of 12 studies involving 270 patients with intractable epilepsy demonstrated a combined efficacy of $42 \%$; however compliance was low [101]. Adequate ketosis is assessed through measuring urine and serum ketones. In our experience, involvement of dietary specialists is necessary to achieve and maintain ketogenesis in the ICU.

\section{Hypothermia}

Therapeutic hypothermia (TH) has long been an attractive treatment for brain injury, owing to a broad spectrum of activity that includes a reduction in inflammation, cerebral metabolic rate, oxidative stress, and cerebral edema. Early models of SE demonstrated anti-seizure and neuroprotective properties of TH $[102,103]$; however, until recently, there were only case reports to describe $\mathrm{TH}$ in human SRSE $[99,104]$. There has since been one multicentered randomized clinical trial comparing TH (goal, $32^{\circ} \mathrm{C}$ to $34^{\circ} \mathrm{C}$ for 24 hours) to standard medical treatment [105]. In the study of 270 patients, the rate of progression to EEG-confirmed SE on the first day was lower in the TH group; however, there was no significant difference between groups in 90-day outcomes. Some neurointensivists believe the effect of TH to be short-lasting, and should be used with caution in light of numerous adverse effects associated with systemic cooling and unclear efficacy $[104,105]$.

\section{Electroconvulsive therapy}

Electroconvulsive therapy is rarely used in the manage- ment of SRSE. This is a result of lacking data to support its use, limited availability in the ICU, and overall inexperience by most neurointensivists. A recent systemic review for electroconvulsive therapy for RSE identified 14 retrospective studies including a total of 19 patients. The review found seizure reduction in $57.9 \%$, but highlighted the low quality of evidence in the current literature [106].

\section{(2) Role of surgical evaluation and treatment}

\section{Surgical evaluation}

When AEDs fail to control SRSE, surgical evaluation should be considered. In patients with a known etiologic structural lesion, early neurosurgical consultation is recommended; however, in the absence of such lesions, work-up and surgical management is challenging. The optimal timing for surgery is unknown, but some authors have suggested evaluation is appropriate after 2 weeks of failed medical therapy [107]. Future study should further identify criteria to select patients most likely to benefit from surgical intervention.

Determining epileptogenic focality on EEG is typically the first diagnostic step. Lateralized and focal epileptiform discharges or seizures suggest a cortical target, while larger regionalized and widespread abnormalities suggest a deeper seizure focus, or diffuse or multi-focal injury. High resolution magnetic resonance imaging with and without contrast is recommended in all SRSE patients when feasible. Common findings include periictal edema and T2-weighted hyperintensities. Diffusionweighted imaging lesions may reverse, while persistent changes signify irreversible neuronal damage and gliosis [108]. Ictal and inter-ictal positron emission tomography and single-photon emission computed tomography have been used in several case reports [109-112]. If a surgical lesion is suggested by non-invasive diagnostic studies, subdural EEG grid placement is necessary to further define the target and map eloquent brain regions.

\section{Electrical stimulation therapies}

Vagal nerve stimulator placement has been described in the treatment of RSE in both children and adults. It 
is appealing for its widespread and tonic effect, while avoiding intracranial instrumentation. A recent systematic review identified 17 studies describing 28 patients, and found vagal nerve stimulator to be potentially effective in generalized RSE, but with poor response in focal RSE [113]. Deep brain stimulation and responsive neurostimulation may be the subject of future interest, but no recommendation for their use can be currently given.

\section{Focal resection and subpial transection}

In adults, focal resection and multiple subpial transections can be considered if a cortical target separated from eloquent brain regions is identified. It is the subject of a number of case reports [109-112], but the exact prevalence of these surgeries is unknown.

Future investigations of electrical stimulation and surgery for SRSE will require combined interest from neurointensivists, epileptologists, and neurosurgeons. Whether earlier surgical evaluation is effective in terminating SRSE and improving patient outcomes should be determined.

\section{Monitoring and Management of Complications}

Neurointensivists are responsible for considering the risks and benefits of any treatment. Expecting and managing complications is important in SRSE, where favorable outcomes are possible even after weeks-to-months of therapeutic coma, especially when no irreversible disease is found. A systemic review of RSE cases suggests longer SE duration is associated with worse outcomes; however, it is unknown if this is a result of the treatment itself, the underlying cause, or complications that arise with prolonged therapy [114].

Following termination of prolonged convulsive seizures, patients should be monitored for rhabdomyolysis and renal injury, affecting the choice of AED. Direct adverse effects of medications include cardiac arrhythmia, hypotension, transaminitis, renal injury, and cutaneous reactions. The risk of complications increases substantially with use of polytherapy and anesthetic agents.
Because patients are often in coma, clinical manifestations of adverse events may be blunted. Patients on highdose anesthetics, particularly propofol, should have serial chemistries and trigylcerides followed.

Indirect adverse effects from prolonged sedation are cause of significant morbidity and mortality in SRSE. Most concerning to neurointensivists, immunosuppression from anesthetic therapy increases the risk of nosocomial infection by 3 -fold [115]. Prolonged immobility additionally increases susceptibility to venous thromboembolism, paralytic ileus and decubitus ulcer formation [49]. Rarely, if attention is not paid to the duration of cEEG monitoring, clinically significant scalp ulcerations can occur. An EEG 'vacation' should be considered after extended monitoring if no drug titration is expected and EEG findings are unlikely to change management.

\section{Conclusions}

SE and RSE are complex neurologic conditions. Although much has been learned from animal models, the pathophysiology of SRSE is still largely unknown. In a large proportion of cases, no underlying cause is found. There are increasingly more drug options to treat SE, but rational polytherapy should consider the pharmacodynamics and kinetics of established and new antiepileptic drugs. When seizures cannot be controlled with conventional medical therapy, non-conventional treatments, including early surgical evaluation can be considered; however, high-quality evidence for these strategies are lacking. Neurointensivists are challenged to reduce secondary brain injury by managing common complications. Future research should aim to identify specific drug regiments that are most effective, and to select which patients will most benefit from alternate therapies.

\section{ORCID}

Gene Sung 


\section{References}

1. Dham BS, Hunter K, Rincon F. The epidemiology of status epilepticus in the United States. Neurocrit Care 2014;20:476-83.

2. Penberthy LT, Towne A, Garnett LK, Perlin JB, DeLorenzo RJ. Estimating the economic burden of status epilepticus to the health care system. Seizure 2005; 14:46-51.

3. Strzelczyk A, Knake S, Oertel WH, Rosenow F, Hamer HM. Inpatient treatment costs of status epilepticus in adults in Germany. Seizure 2013;22:882-5.

4. Gastaut H. Clinical and electroencephalographical classification of epileptic seizures. Epilepsia 1970;11:102-13.

5. Brodie MJ. Status epilepticus in adults. Lancet 1990;336:551-2.

6. Meldrum BS, Horton RW. Physiology of status epilepticus in primates. Arch Neurol 1973;28:1-9.

7. Trinka E, Cock H, Hesdorffer D, Rossetti AO, Scheffer IE, Shinnar S, et al. A definition and classification of status epilepticus: report of the ILAE Task Force on Classification of Status Epilepticus. Epilepsia 2015;56:1515-23.

8. Lowenstein DH, Alldredge BK. Status epilepticus. N Engl J Med 1998;338:970-6.

9. Brophy GM, Bell R, Claassen J, Alldredge B, Bleck $\mathrm{TP}$, Glauser T, et al. Guidelines for the evaluation and management of status epilepticus. Neurocrit Care 2012;17:3-23.

10. Mayer SA, Claassen J, Lokin J, Mendelsohn F, Dennis LJ, Fitzsimmons BF. Refractory status epilepticus: frequency, risk factors, and impact on outcome. Arch Neurol 2002;59:205-10.

11. Holtkamp M, Othman J, Buchheim K, Meierkord H. Predictors and prognosis of refractory status epilepticus treated in a neurological intensive care unit. J Neurol Neurosurg Psychiatry 2005;76:534-9.

12. Ferlisi M, Shorvon S. The outcome of therapies in refractory and super-refractory convulsive status epilepticus and recommendations for therapy. Brain
2012;135(Pt 8):2314-28.

13. Beg JM, Anderson TD, Francis K, Meckley LM, Fitzhenry D, Foster T, et al. Burden of illness for super-refractory status epilepticus patients. J Med Econ 2017;20:45-53.

14. Gaspard N, Foreman BP, Alvarez V, Cabrera Kang C, Probasco JC, Jongeling AC, et al. New-onset refractory status epilepticus: etiology, clinical features, and outcome. Neurology 2015;85:1604-13.

15. DeLorenzo RJ, Pellock JM, Towne AR, Boggs JG. Epidemiology of status epilepticus. J Clin Neurophysiol 1995;12:316-25.

16. DeLorenzo RJ, Towne AR, Pellock JM, Ko D. Status epilepticus in children, adults, and the elderly. Epilepsia 1992;33 Suppl 4:S15-25.

17. Shinnar S, Pellock JM, Moshé SL, Maytal J, O’Dell C, Driscoll SM, et al. In whom does status epilepticus occur: age-related differences in children. Epilepsia 1997;38:907-14

18. Glaser CA, Gilliam S, Honarmand S, Tureen JH, Lowenstein DH, Anderson LJ, et al. Refractory status epilepticus in suspect encephalitis. Neurocrit Care 2008;9:74-82.

19. Van Lierde I, Van Paesschen W, Dupont P, Maes A, Sciot R. De novo cryptogenic refractory multifocal febrile status epilepticus in the young adult: a review of six cases. Acta Neurol Belg 2003;103:88-94.

20. Wilder-Smith EP, Lim EC, Teoh HL, Sharma VK, Tan JJ, Chan BP, et al. The NORSE (new-onset refractory status epilepticus) syndrome: defining a disease entity. Ann Acad Med Singapore 2005;34:417-20.

21. Hoerth MT, Sirven JI, Drazkowski JF, Noe KH. Malignant status epilepticus syndrome: refractory idiopathic status epilepticus. Epilepsia 2007;48:P012.

22. Costello DJ, Kilbride RD, Cole AJ. Cryptogenic New Onset Refractory Status Epilepticus (NORSE) in adults: infectious or not? J Neurol Sci 2009;277:26-31.

23. Holmes GL, Ben-Ari Y. Seizing hold of seizures. Nat Med 2003;9:994-6.

24. Chen JW, Naylor DE, Wasterlain CG. Advances in the pathophysiology of status epilepticus. Acta Neu- 
rol Scand 2007;115(4 Suppl):7-15.

25. Mazarati AM, Baldwin RA, Sankar R, Wasterlain CG. Time-dependent decrease in the effectiveness of antiepileptic drugs during the course of self-sustaining status epilepticus. Brain Res 1998;814:179-85.

26. Theodore WH, Porter RJ, Albert P, Kelley K, Bromfield E, Devinsky $\mathrm{O}$, et al. The secondarily generalized tonic-clonic seizure: a videotape analysis. Neurology 1994;44:1403-7.

27. Mazarati AM, Liu H, Soomets U, Sankar R, Shin D, Katsumori H, et al. Galanin modulation of seizures and seizure modulation of hippocampal galanin in animal models of status epilepticus. J Neurosci 1998;18:10070-7.

28. Mazarati A, Liu H, Wasterlain C. Opioid peptide pharmacology and immunocytochemistry in an animal model of self-sustaining status epilepticus. Neuroscience 1999;89:167-73.

29. Liu H, Mazarati AM, Katsumori H, Sankar R, Wasterlain CG. Substance P is expressed in hippocampal principal neurons during status epilepticus and plays a critical role in the maintenance of status epilepticus. Proc Natl Acad Sci U S A 1999;96:5286-91.

30. Vezzani A, Sperk G, Colmers WF. Neuropeptide Y: emerging evidence for a functional role in seizure modulation. Trends Neurosci 1999;22:25-30.

31. Meldrum BS, Vigouroux RA, Brierley JB. Systemic factors and epileptic brain damage: prolonged seizures in paralyzed, artificially ventilated baboons. Arch Neurol 1973;29:82-7.

32. Meldrum BS, Brierley JB. Prolonged epileptic seizures in primates: ischemic cell change and its relation to ictal physiological events. Arch Neurol 1973;28:10-7.

33. Nevander G, Ingvar M, Auer R, Siesjö BK. Status epilepticus in well-oxygenated rats causes neuronal necrosis. Ann Neurol 1985;18:281-90.

34. Wasterlain CG, Fujikawa DG, Penix L, Sankar R. Pathophysiological mechanisms of brain damage from status epilepticus. Epilepsia 1993;34 Suppl 1:S37-53.
35. Pollard H, Charriaut-Marlangue C, Cantagrel S, Represa A, Robain O, Moreau J, et al. Kainateinduced apoptotic cell death in hippocampal neurons. Neuroscience 1994;63:7-18.

36. Niquet J, Baldwin RA, Allen SG, Fujikawa DG, Wasterlain CG. Hypoxic neuronal necrosis: protein synthesis-independent activation of a cell death program. Proc Natl Acad Sci U S A 2003;100:2825-30.

37. DeGiorgio CM, Correale JD, Gott PS, Ginsburg DL, Bracht KA, Smith T, et al. Serum neuron-specific enolase in human status epilepticus. Neurology 1995;45:1134-7.

38. DeGiorgio CM, Heck CN, Rabinowicz AL, Gott PS, Smith T, Correale J. Serum neuron-specific enolase in the major subtypes of status epilepticus. Neurology 1999;52:746-9.

39. Corsellis JA, Bruton CJ. Neuropathology of status epilepticus in humans. Adv Neurol 1983;34:129-39.

40. Engel J Jr, Ludwig BI, Fetell M. Prolonged partial complex status epilepticus: EEG and behavioral observations. Neurology 1978;28(9 Pt 1):863-9.

41. DeGiorgio CM, Gott PS, Rabinowicz AL, Heck CN, Smith TD, Correale JD. Neuron-specific enolase, a marker of acute neuronal injury, is increased in complex partial status epilepticus. Epilepsia 1996;37:606-9.

42. Rabinowicz AL, Correale JD, Bracht KA, Smith TD, DeGiorgio CM. Neuron-specific enolase is increased after nonconvulsive status epilepticus. Epilepsia 1995;36:475-9.

43. Shirasaka Y. Lack of neuronal damage in atypical absence status epilepticus. Epilepsia 2002;43:1498-501.

44. Cockerell OC, Walker MC, Sander JW, Shorvon SD. Complex partial status epilepticus: a recurrent problem. J Neurol Neurosurg Psychiatry 1994;57:835-7.

45. Cherian A, Thomas SV. Status epilepticus. Ann Indian Acad Neurol 2009;12:140-53.

46. Lothman E. The biochemical basis and pathophysiology of status epilepticus. Neurology 1990;40(5 Suppl 2):13-23.

47. Claassen J, Mayer SA, Kowalski RG, Emerson RG, Hirsch LJ. Detection of electrographic seizures with 
continuous EEG monitoring in critically ill patients. Neurology 2004;62:1743-8.

48. Schmitt SE. Utility of clinical features for the diagnosis of seizures in the intensive care unit. J Clin Neurophysiol 2017;34:158-61.

49. Bleck TP. Status epilepticus and the use of continuous EEG monitoring in the intensive care unit. Continuum (Minneap Minn) 2012;18:560-78.

50. Wittman JJ Jr, Hirsch LJ. Continuous electroencephalogram monitoring in the critically ill. Neurocrit Care 2005;2:330-41.

51. Friedman D, Claassen J, Hirsch LJ. Continuous electroencephalogram monitoring in the intensive care unit. Anesth Analg 2009;109:506-23.

52. Laccheo I, Sonmezturk H, Bhatt AB, Tomycz L, Shi Y, Ringel M, et al. Non-convulsive status epilepticus and non-convulsive seizures in neurological ICU patients. Neurocrit Care 2015;22:202-11.

53. Towne AR, Waterhouse EJ, Boggs JG, Garnett LK, Brown AJ, Smith JR Jr, et al. Prevalence of nonconvulsive status epilepticus in comatose patients. Neurology 2000;54:340-5.

54. Westover MB, Shafi MM, Bianchi MT, Moura LM, O'Rourke D, Rosenthal ES, et al. The probability of seizures during EEG monitoring in critically ill adults. Clin Neurophysiol 2015;126:463-71.

55. Swisher CB, Shah D, Sinha SR, Husain AM. Baseline EEG pattern on continuous ICU EEG monitoring and incidence of seizures. J Clin Neurophysiol 2015;32:147-51.

56. Shafi MM, Westover MB, Cole AJ, Kilbride RD, Hoch DB, Cash SS. Absence of early epileptiform abnormalities predicts lack of seizures on continuous EEG. Neurology 2012;79:1796-801.

57. Glauser T, Shinnar S, Gloss D, Alldredge B, Arya $\mathrm{R}$, Bainbridge $\mathrm{J}$, et al. Evidence-based guideline: treatment of convulsive status epilepticus in children and adults. Report of the Guideline Committee of the American Epilepsy Society. Epilepsy Curr 2016;16:48-61.

58. Treiman DM, Meyers PD, Walton NY, Collins JF,
Colling C, Rowan AJ, et al. A comparison of four treatments for generalized convulsive status epilepticus: Veterans Affairs Status Epilepticus Cooperative Study Group. N Engl J Med 1998;339:792-8.

59. Trinka E, Höfler J, Leitinger M, Brigo F. Pharmacotherapy for status epilepticus. Drugs 2015;75:1499-521.

60. Cranford RE, Leppik IE, Patrick B, Anderson CB, Kostick B. Intravenous phenytoin in acute treatment of seizures. Neurology 1979;29:1474-9.

61. Patsalos PN. Clinical pharmacokinetics of levetiracetam. Clin Pharmacokinet 2004;43:707-24.

62. Misra UK, Kalita J, Maurya PK. Levetiracetam versus lorazepam in status epilepticus: a randomized, open labeled pilot study. J Neurol 2012;259:645-8.

63. Yasiry Z, Shorvon SD. The relative effectiveness of five antiepileptic drugs in treatment of benzodiazepineresistant convulsive status epilepticus: a meta-analysis of published studies. Seizure 2014;23:167-74.

64. Claassen J, Hirsch LJ, Emerson RG, Mayer SA. Treatment of refractory status epilepticus with pentobarbital, propofol, or midazolam: a systematic review. Epilepsia 2002;43:146-53.

65. Singhi S, Murthy A, Singhi P, Jayashree M. Continuous midazolam versus diazepam infusion for refractory convulsive status epilepticus. J Child Neurol 2002;17:106-10.

66. Kumar A, Bleck TP. Intravenous midazolam for the treatment of refractory status epilepticus. Crit Care Med 1992;20:483-8.

67. Stover JF, Stocker R. Barbiturate coma may promote reversible bone marrow suppression in patients with severe isolated traumatic brain injury. Eur J Clin Pharmacol 1998;54:529-34.

68. Melamed R, Bar-Yosef S, Shakhar G, Shakhar K, Ben-Eliyahu S. Suppression of natural killer cell activity and promotion of tumor metastasis by ketamine, thiopental, and halothane, but not by propofol: mediating mechanisms and prophylactic measures. Anesth Analg 2003;97:1331-9.

69. Krishnamurthy KB, Drislane FW. Depth of EEG suppression and outcome in barbiturate anesthetic 
treatment for refractory status epilepticus. Epilepsia 1999;40:759-62.

70. Rossetti AO, Logroscino G, Bromfield EB. Refractory status epilepticus: effect of treatment aggressiveness on prognosis. Arch Neurol 2005;62:1698-702.

71. Bourgeois BF. Pharmacokinetic properties of current antiepileptic drugs: what improvements are needed? Neurology 2000;55(11 Suppl 3):S11-6.

72. Ramael S, De Smedt F, Toublanc N, Otoul C, Boulanger P, Riethuisen JM, et al. Single-dose bioavailability of levetiracetam intravenous infusion relative to oral tablets and multiple-dose pharmacokinetics and tolerability of levetiracetam intravenous infusion compared with placebo in healthy subjects. Clin Ther 2006;28:734-44.

73. Smith BS, Yogaratnam D, Levasseur-Franklin KE, Forni A, Fong J. Introduction to drug pharmacokinetics in the critically ill patient. Chest 2012;141:1327-36.

74. Swadron SP, Rudis MI, Azimian K, Beringer P, Fort D, Orlinsky M. A comparison of phenytoin-loading techniques in the emergency department. Acad Emerg Med 2004;11:244-52.

75. May T, Rambeck B. Serum concentrations of valproic acid: influence of dose and comedication. Ther Drug Monit 1985;7:387-90.

76. Perucca E. Clinically relevant drug interactions with antiepileptic drugs. Br J Clin Pharmacol 2006;61:246-55.

77. Wasterlain CG, Baldwin R, Naylor DE, Thompson KW, Suchomelova L, Niquet J. Rational polytherapy in the treatment of acute seizures and status epilepticus. Epilepsia 2011;52 Suppl 8:70-1.

78. Abend NS, Dlugos DJ. Treatment of refractory status epilepticus: literature review and a proposed protocol. Pediatr Neurol 2008;38:377-90.

79. Lee JW, Dworetzky B. Rational polytherapy with antiepileptic drugs. Pharmaceuticals (Basel) 2010;3:2362-79.

80. Gillard M, Fuks B, Leclercq K, Matagne A. Binding characteristics of brivaracetam, a selective, high affinity SV2A ligand in rat, mouse and human brain: relationship to anti-convulsant properties. Eur J Phar- macol 2011;664:36-44.

81. Nicolas JM, Hannestad J, Holden D, Kervyn S, Nabulsi N, Tytgat $\mathrm{D}$, et al. Brivaracetam, a selective highaffinity synaptic vesicle protein 2A (SV2A) ligand with preclinical evidence of high brain permeability and fast onset of action. Epilepsia 2016;57:201-9.

82. Wasterlain C, Suchomelova L, Matagne A, Klitgaard $\mathrm{H}$, Mazarati A, Shinmei S, et al. Brivaracetam is a potent anticonvulsant in experimental status epilepticus. Epilepsia 2005;46(suppl 8):219-20.

83. Rogawski MA, Loya CM, Reddy K, Zolkowska D, Lossin C. Neuroactive steroids for the treatment of status epilepticus. Epilepsia 2013;54 Suppl 6:93-8.

84. Vaitkevicius H, Ng M, Moura L, Rosenthal E, Westover MB, Rosand J, et al. Successful allopregnanolone treatment of new onset refractory status epilepticus (NORSE) syndrome: first in man experience. Epilepsia 2013;54(suppl 6):106-24.

85. Broomall E, Natale JE, Grimason M, Goldstein J, Smith CM, Chang C, et al. Pediatric super-refractory status epilepticus treated with allopregnanolone. Ann Neurol 2014;76:911-5.

86. Sage Therapeutics. A study with SAGE-547 for super-refractory status epilepticus [Internet]. Bethesda (MD): U.S. National Library of Medicine; 2000 [cited 2016 Nov 12]. Available from: https://clinicaltrials. gov/ct2/show/NCT02477618?term=NCT02477618\& rank $=1$.

87. White HS, Alex AB, Pollock A, Hen N, Shekh-Ahmad T, Wilcox KS, et al. A new derivative of valproic acid amide possesses a broad-spectrum antiseizure profile and unique activity against status epilepticus and organophosphate neuronal damage. Epilepsia 2012;53:134-46.

88. Bar-Klein G, Swissa E, Kamintsky L, Shekh-Ahmad T, Saar-Ashkenazy R, Hubary Y, et al. sec-Butylpropylacetamide (SPD) and two of its stereoisomers rapidly terminate paraoxon-induced status epilepticus in rats. Epilepsia 2014;55:1953-8.

89. Novak GP, Kelley M, Zannikos P, Klein B. Carisbamate (RWJ-333369). Neurotherapeutics 
2007;4:106-9.

90. Francois J, Ferrandon A, Koning E, Nehlig A. A new drug RWJ 333369 protects limbic areas in the lithium-pilocarpine model (li-pilo) of epilepsy and delays or prevents the occurrence of spontaneous seizures. Epilepsia 2005;46(suppl 8):269-70.

91. Synowiec AS, Singh DS, Yenugadhati V, Valeriano JP, Schramke CJ, Kelly KM. Ketamine use in the treatment of refractory status epilepticus. Epilepsy Res 2013;105:183-8.

92. Gaspard N, Foreman B, Judd LM, Brenton JN, Nathan BR, McCoy BM, et al. Intravenous ketamine for the treatment of refractory status epilepticus: a retrospective multicenter study. Epilepsia 2013;54:1498-503.

93. Kramer AH. Early ketamine to treat refractory status epilepticus. Neurocrit Care 2012;16:299-305.

94. Kofke WA, Young RS, Davis P, Woelfel SK, Gray L, Johnson D, et al. Isoflurane for refractory status epilepticus: a clinical series. Anesthesiology 1989;71:653-9.

95. Mirsattari SM, Sharpe MD, Young GB. Treatment of refractory status epilepticus with inhalational anesthetic agents isoflurane and desflurane. Arch Neurol 2004;61:1254-9.

96. Zhumadilov A, Gilman CP, Viderman D. Management of super-refractory status epilepticus with isoflurane and hypothermia. Front Neurol 2015;5:286.

97. Varvel NH, Neher JJ, Bosch A, Wang W, Ransohoff RM, Miller RJ, et al. Infiltrating monocytes promote brain inflammation and exacerbate neuronal damage after status epilepticus. Proc Natl Acad Sci U S A 2016;113:E5665-74.

98. Alyu F, Dikmen M. Inflammatory aspects of epileptogenesis: contribution of molecular inflammatory mechanisms. Acta Neuropsychiatr 2017;29:1-16.

99. Shorvon S, Ferlisi M. The treatment of super-refractory status epilepticus: a critical review of available therapies and a clinical treatment protocol. Brain 2011;134(Pt 10):2802-18.

100. Thakur KT, Probasco JC, Hocker SE, Roehl K, Henry $\mathrm{B}$, Kossoff $\mathrm{EH}$, et al. Ketogenic diet for adults in super-refractory status epilepticus. Neurology 2014;82:665-70.

101. Ye F, Li XJ, Jiang WL, Sun HB, Liu J. Efficacy of and patient compliance with a ketogenic diet in adults with intractable epilepsy: a meta-analysis. J Clin Neurol 2015;11:26-31.

102. Liu Z, Gatt A, Mikati M, Holmes GL. Effect of temperature on kainic acid-induced seizures. Brain Res 1993;631:51-8.

103. Lundgren J, Smith ML, Blennow G, Siesjo BK. Hyperthermia aggravates and hypothermia ameliorates epileptic brain damage. Exp Brain Res 1994;99:43-55.

104. Corry JJ, Dhar R, Murphy T, Diringer MN. Hypothermia for refractory status epilepticus. Neurocrit Care 2008;9:189-97.

105. Legriel S, Lemiale V, Schenck M, Chelly J, Laurent V, Daviaud F, et al. Hypothermia for neuroprotection in convulsive status epilepticus. N Engl J Med 2016;375:2457-67.

106. Zeiler FA, Matuszczak M, Teitelbaum J, Gillman LM, Kazina CJ. Electroconvulsive therapy for refractory status epilepticus: a systematic review. Seizure 2016;35:23-32.

107. Lhatoo SD, Alexopoulos AV. The surgical treatment of status epilepticus. Epilepsia 2007;48 Suppl 8:61-5.

108. Mendes A, Sampaio L. Brain magnetic resonance in status epilepticus: a focused review. Seizure 2016;38:63-7.

109. MD’Giano CH, Del C García M, Pomata H, Rabinowicz AL. Treatment of refractory partial status epilepticus with multiple subpial transection: case report. Seizure 2001;10:382-5.

110. Ma X, Liporace J, O’Connor MJ, Sperling MR. Neurosurgical treatment of medically intractable status epilepticus. Epilepsy Res 2001;46:33-8.

111. Ng YT, Kerrigan JF, Rekate HL. Neurosurgical treatment of status epilepticus. J Neurosurg 2006;105(5 Suppl):378-81.

112. Dillien P, Ferrao Santos S, van Pesch V, Suin V, Lamoral S, Hantson P. New-onset refractory status epilepticus: more investigations, more questions. 
Case Rep Neurol 2016;8:127-33.

113. Zeiler FA, Zeiler KJ, Teitelbaum J, Gillman LM, West M. VNS for refractory status epilepticus. Epilepsy Res 2015;112:100-13.

114. Neligan A, Shorvon SD. Frequency and prognosis of convulsive status epilepticus of different causes: a systematic review. Arch Neurol 2010;67:931-40.

115. Sutter R, Marsch S, Fuhr P, Kaplan PW, Ruegg S. Anesthetic drugs in status epilepticus: risk or rescue? A 6-year cohort study. Neurology 2014;82:656-64. 